Российская академия наук · Уральское отделение

Минералогия техногенеза-2020

\title{
НОВЫЕ ДАННЫЕ О ТЕХНОГЕННОМ МИНЕРАЛООБРАЗОАНИИ НА ЧИТИНСКОЙ ТЭЦ-1
}

\author{
Р. А. Филенко ${ }^{1,2}$, Г. А. Юргенсон ${ }^{1,2}$, Н. П. Сигачев ${ }^{1,2}$ \\ ${ }^{1}$ Институт природных ресурсов, экологии и криологии СО РАН, \\ 2. Чита. \\ 23абайкальский государственный университет, г. Чита
}

\section{Введение}

Читинская ТЭЦ-1 (до 1982 г. Читинская ГРЭС) в г. Чита находится на берегу озера Кенон, служащего для неё водоёмом-охладителем. Входит в ТГК-14, являясь самой её большой и крупнейшей в Забайкалье электростанцией. ТЭЦ обеспечивает электроснабжение г. Чита и выдачу электроэнергии в общую сеть по линиям 220/110 кВ, централизованным теплоснабжением на 80 \% потребности краевого центра и пос. Энергетиков и КСК. На Читинской ТЭЦ-1 установлено 12 котельных агрегатов БКЗ-220-100Ф и 1 реконструированный котельный агрегат БКЗ-240-100Ф, 2 турбины ПТ-60-90, одна турбина Т-80-90 (бывшая К-100-90), две турбины Т-87-90 и одна турбина Т-97-90 (бывшие К-10090), 3 электрические машины ТВФ-100-2, 2 электрические машины ТВФ-60-2 и одна электрическая машина ТВФ-120-2. Основным топливным источником, под который проектировалась Читинская ГРЭС, было Харанорское месторождение бурых углей, пригодное для обработки открытым способом. В состав поставщиков на Читинскую ТЭЦ-1 входят также Татауровский и Уртуйский угольные разрезы.

В 2018 г. руководство ТЭЦ-1 обратилось в ИПРЭК СО РАН с целью изучения проблемы новообразованных минеральных кор на футерованной поверхности скрубберов и в золошлакопроводах. Ранее [4] нами рассматривалось минералообразование на золошлакоотвалах ТЭЦ-1 и ТЭЦ-2 города Чита, но, как правило, находки минеральных новообразований имели случайный характер. Целенаправленных исследований всей цепочки техногенного минералообразования до этого не проводилось. Необходимость изучения вещества минеральных кор (наростов) заключается в том, что познав состав продуктов техногенного минералообразования, можно выработать рекомендации по мерам снижения или ликвидации этого негативного явления, сказывающегося 
на безаварийности и эффективности работы станции в целом и его отдельных участков в частности.

\section{Материалы и методы}

Для изучения нам был предоставлен свежий образец так называемой зольной коры, отбитый со стенки скруббера. На вид зольная кора представляет собой нарост, состоящий из множества чередующихся светлых и тёмных слоев сцементированной золы (рис. 1). Состав цемента и был главной целью исследования. Первоначально предполагалось, что состав цемента по аналогии с карбонатными образованиями в золошлакопроводах ТЭЦ-1, изученных нами [4] в 2016 г., будет карбонатным.

Для определения минерального состава предоставленный материал был истёрт в агатовой ступке со спиртом и исследован методом порошковой дифракции на рентгеновском дифрактометре ДРОН-3.0, излучение - $\mathrm{CuK} \alpha, \mathrm{Ni}$ - фильтр, V= 25 кB, I = 20 мА, шаг сканирования $-0.05^{\circ}$. Фазовый состав проб расшифрован с помощью программы поиска фаз (Diffracplus, PDF-2, 2007 г) инженером ЦКП «Геодинамика и геохронология» ИЗК СО РАН (г. Иркутск) М. Н. Рубцовой.

При изучении порошковых препаратов техногенных образований применялся сканирующий электронный микроскоп LEO 1430VP (CarlZeiss, Германия) с энергодисперсионным спектрометром INCAEnergy 350 (Oxford InstrumentsAnalytical Ltd.) в ГИН СО РАН (г. Улан-Удэ). Условия съемки - ускоряющее напряжение 20 кВ, ток зон-

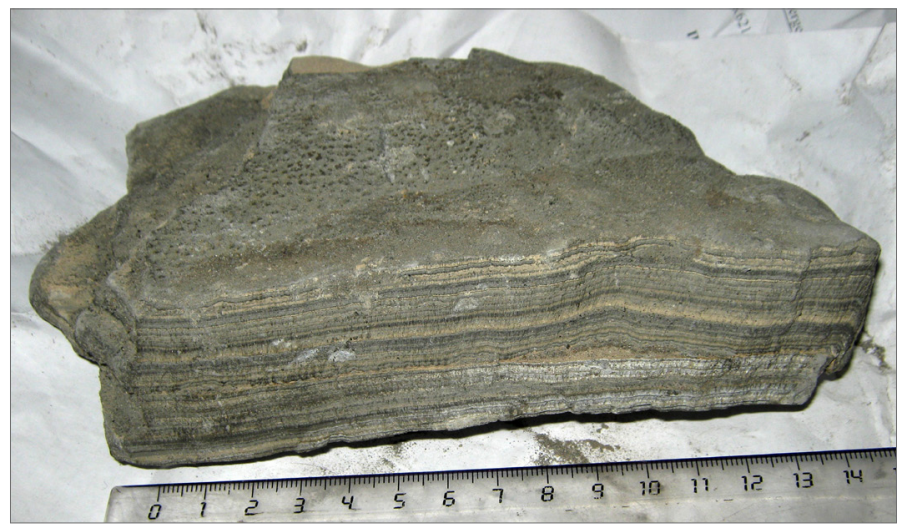

Рис. 1. Образец слоистой минеральной коры из скрубера Читинской ТЭЦ-1 (обр. 3О-18-01, фото Р. Филенко).

Минералогия техногенеза. 2020. № 21. 
да 0.3-0.4 нА, размер зонда $<0.1$ мкм, время измерения 50 секунд (живое время). Ошибка анализа на сумму достигает 2-4 масс. \% в зависимости от качества поверхности образца и особенностей его состава (аналитик Е. А. Хромова).

Инфракрасные спектры регистрировались в лаборатории ЗабГУ на спектрофотометре FTIR-8400S SHIMADZU, который регистрирует инфракрасные спектры пропускания исследуемых проб в диапазоне волновых чисел 4000-400 см-1, в таблетках $\mathrm{KBr}$ (оператор Л. М. Басова)

Синхронный термический анализ проводился на приборе STA 449 F1 Jupiter фирмы NETZSCH (Германия) в ИПРЭК CO PAH. Использовались платиновые тигли. Скорость нагрева во всех измерениях составляла $10^{\circ} \mathrm{C} /$ минуту. Масса исследуемых навесок - 30 мг. В печи создавалась динамичная атмосфера с использованием в качестве продувочных газов в зависимости от задач исследования атмосферного воздуха или сухого аргона с расходом 30 мл/мин. Полученные исходные файлы термограмм, записанных с плотностью 100 точек в минуту, обрабатывались с помощью программного обеспечения NETZSCH Proteus Analysis (v 5.2.1).

\section{Результаты и их обсуждение}

Рентгенофазовый анализ показал (рис. 2a), что в пробе зольных кор из скруббера Читинской ТЭЦ-1 главной и основной фазой является полуводный сульфит кальция - ханнебахит. Основные линии на рентгенограмме соответствуют эталону из базы данных [7] (рис. 2б). Параметры элементарной ячейки ханнебахита: $\mathrm{a}=10.657 \pm 0,008 \AA$,

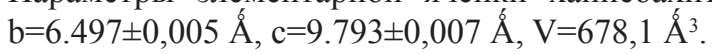

Данные электронной микроскопии порошковых препаратов показали, что в подавляющем большинстве точек анализа вещества состав отвечает ханнебахиту (рис. 3a). В двух точках выявлен сульфат бария барит в виде единичных мелких (до 10 мкм ) зерен среди ханнебахита (рис. 3б).

Так как самым доступным и экспрессным для нас являлся синхронный термический анализ, сделана серия термограмм из разных слоёв зольной коры. При исследовании образца светлого слоя коры наряду с ханнебахитом на термограмме чётко проявилась ступень дегидратации гипса (рис. 4) на начальном этапе нагревания вещества. В среднем потеря массы составляет около $1 \%$, что в пересчете дает $5 \%$ гипса в пробе.

На дифрактограмме этой же зоны коры также видны чёткие пики гипса, наряду с кварцем и преобладающим ханнебахитом (рис. 5). 

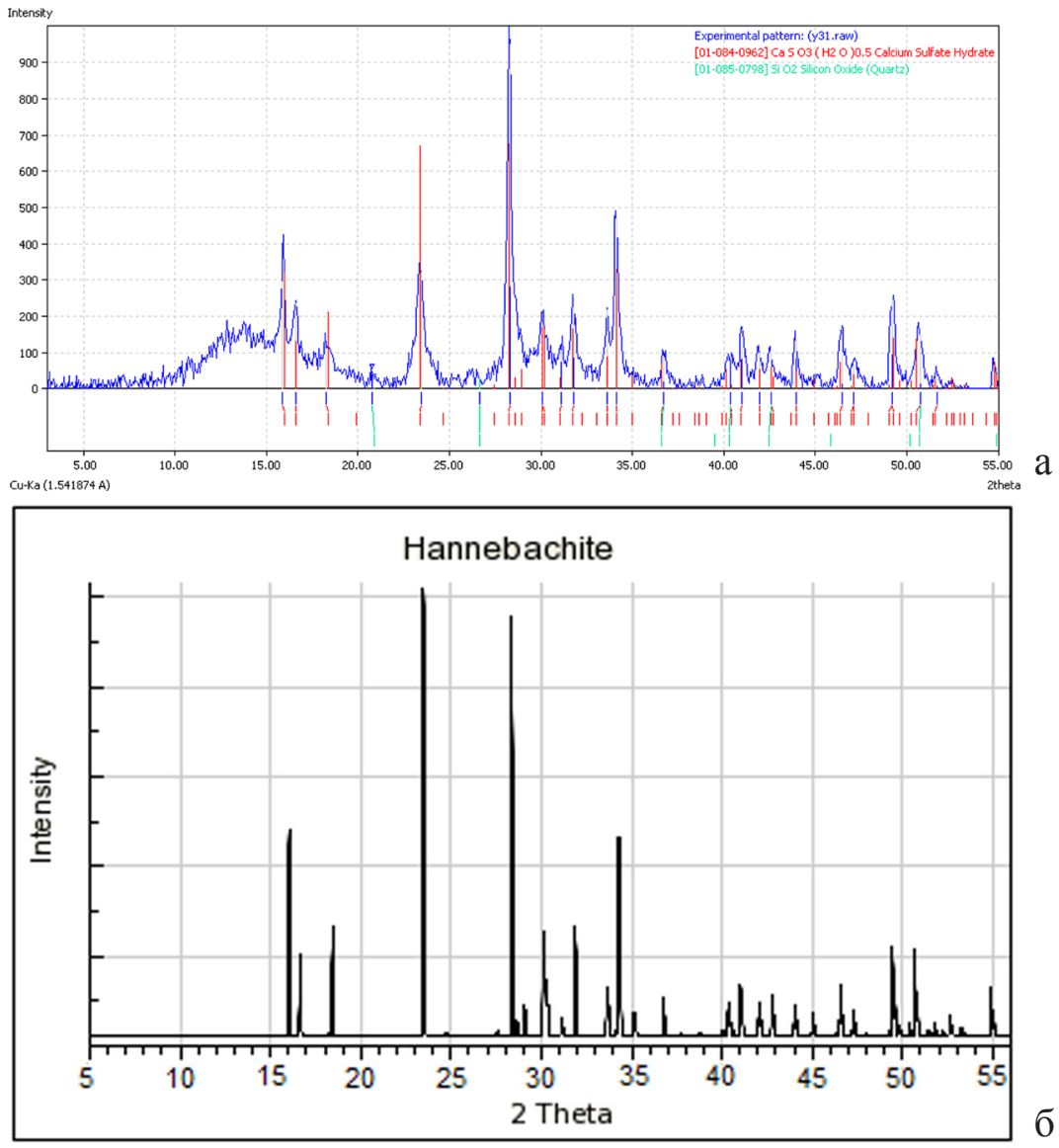

Рис. 2. Дифрактограмма ханнебахита из зольной коры Читинской ТЭЦ-1 (а) и эталонного образца из базы данных [7] (б).

При изучении термического поведения образца зольной коры при нагревании в атмосфере аргона на начальном этапе нагревания наблюдается схожий с пробой, исследованной на воздухе, ход кривых. После ступени дегидратации в интервале $350-450{ }^{\circ} \mathrm{C}$ кривые уже существенно различаются, при этом на ТГ-кривой пробы, снятой на воздухе, наблюдается увеличение массы, сопровождающееся широким двойным экзопиком при 548 и $652{ }^{\circ} \mathrm{C}$ соответственно (рис. 6). В целом, ступень дегидратации исследуемого ханнбахита сопоставима по температур-

Минералогия техногенеза. 2020. № 21. 


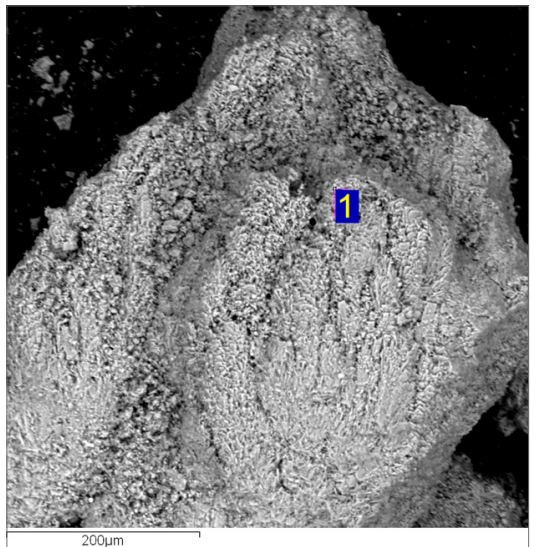

a

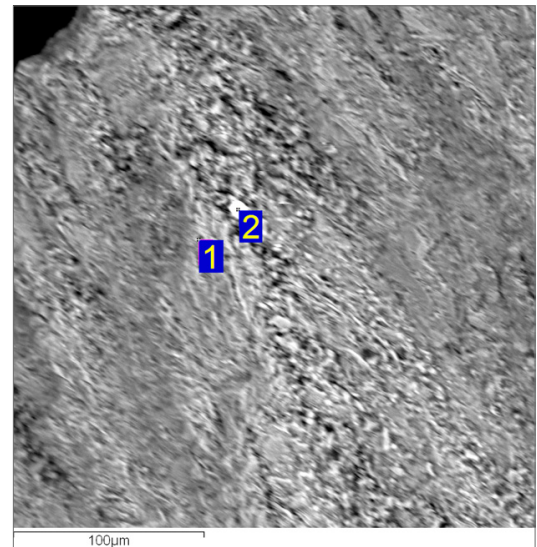

б

Рис. 3. Электронные микрофотографии ханнебахитовой коры: 1 - ханнебахит, 2 - барит.

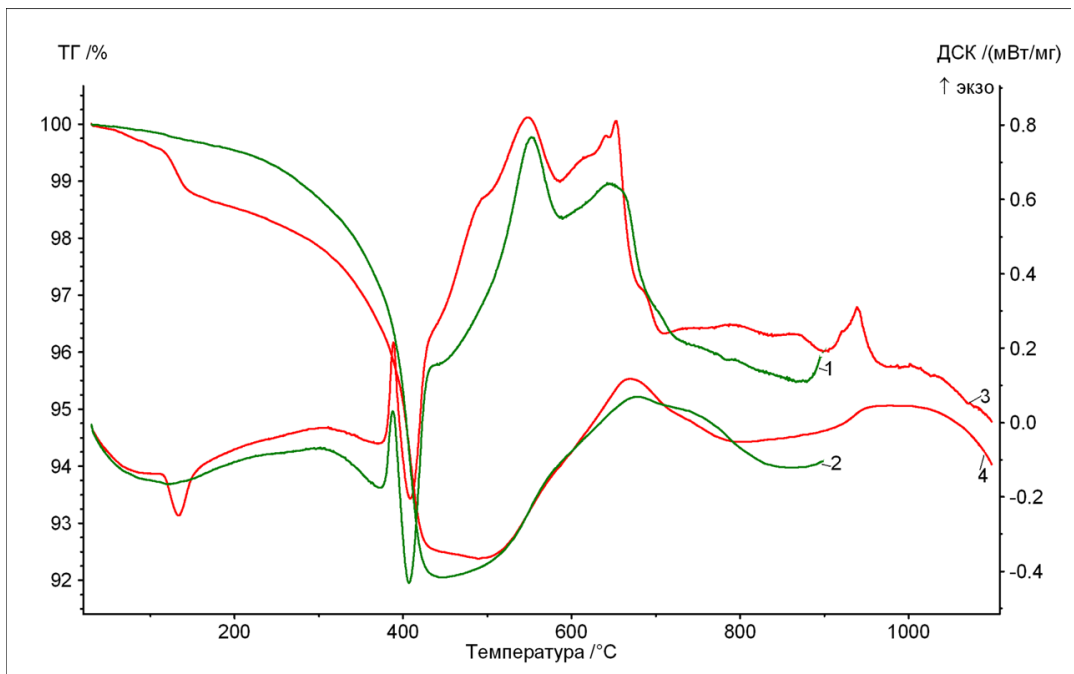

Рис. 4. Термограммы зон зольной коры, сцементированной ханнебахитом $(1,2)$ и ханнебахитом с примесью гипса $(3,4)$. ТГ-кривые $-2,4$; ДСКкривые $-1,3$. 


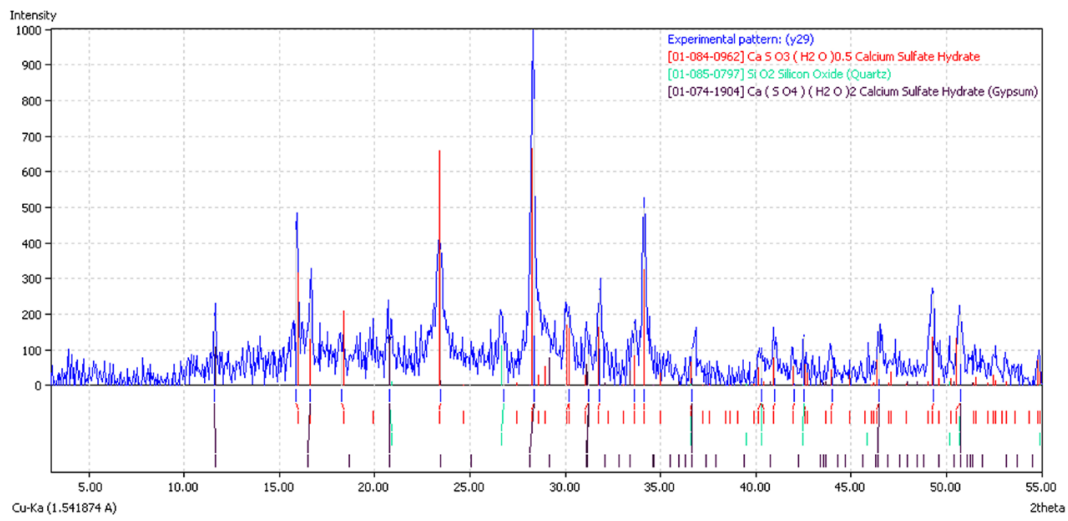

Рис. 5. Дифрактограмма образца зольной коры из Читинской ТЭЦ-1 состоящей из ханнебахита с примесью гипса.

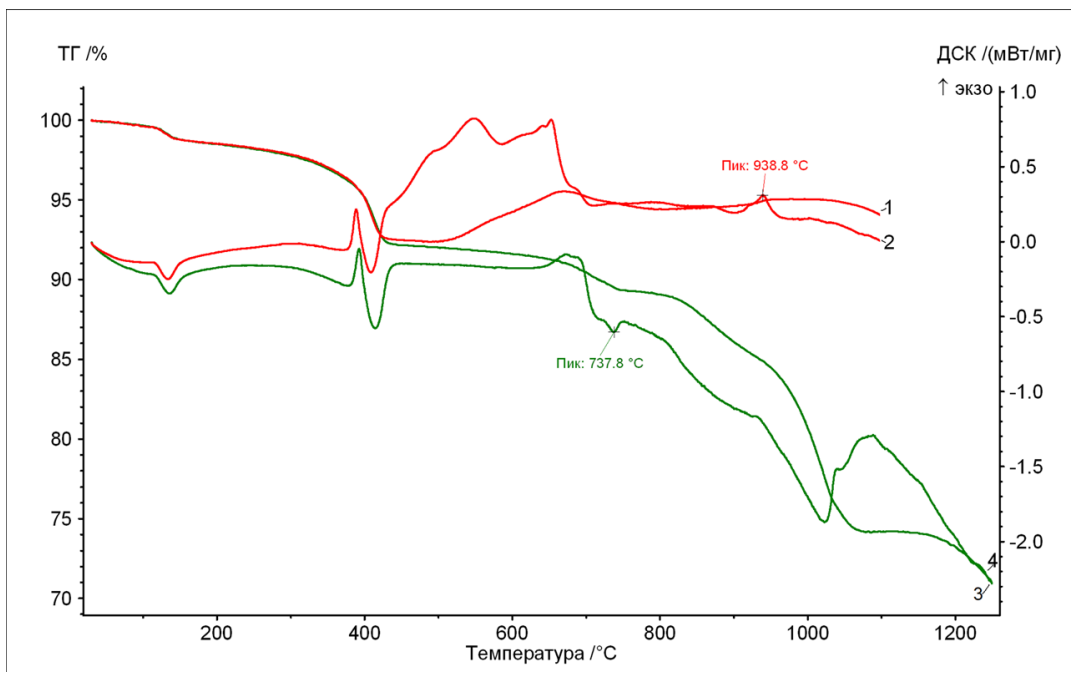

Рис. 6. Термограммы образцов зольной коры, сцементированной ханнебахитом с примесью гипса, снятых на воздухе $(1,2)$ и в атмосфере аргона $(3,4)$. ТГ-кривые - 1, 3; ДСК-кривые - 2, 4 . 

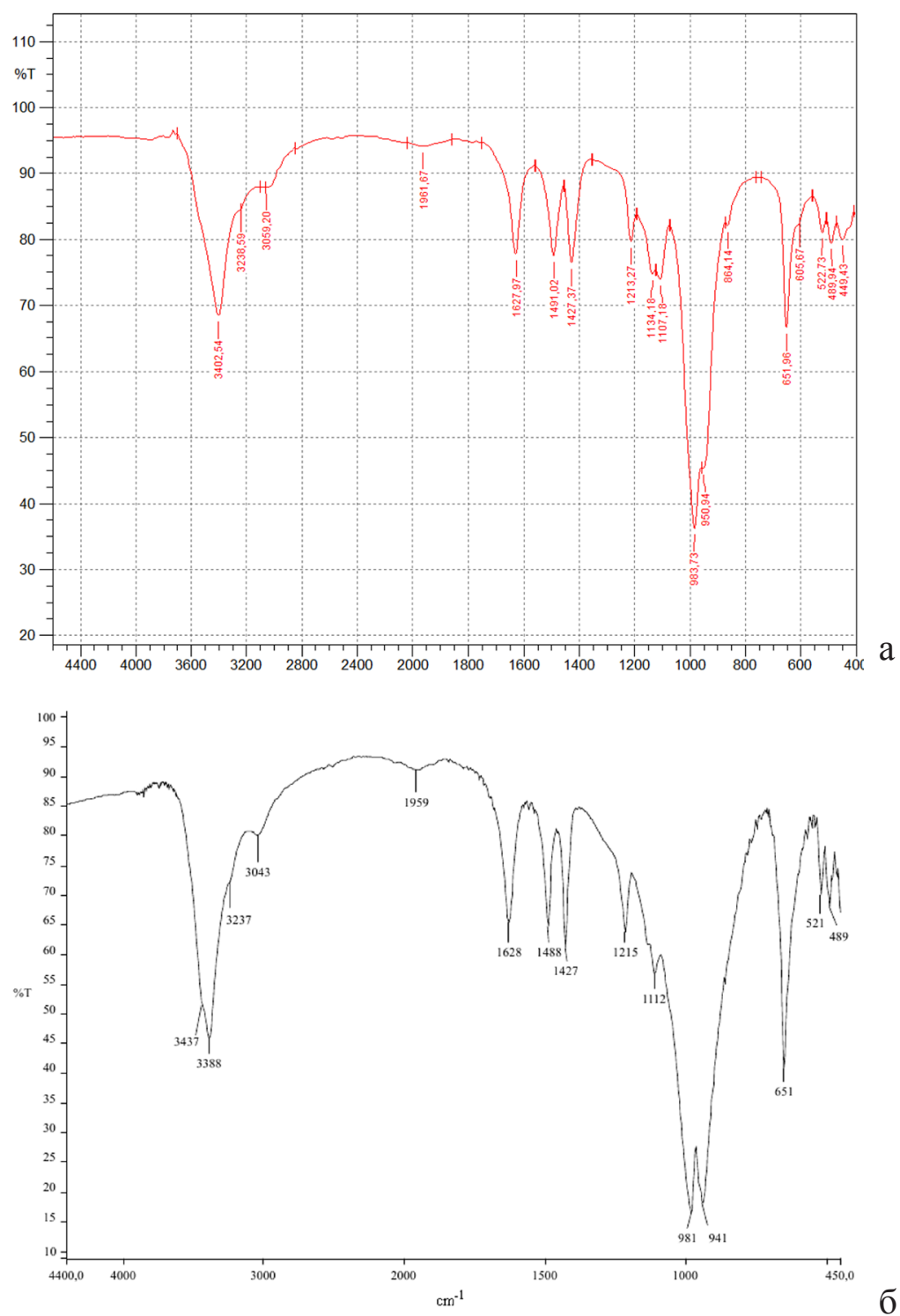

Рис. 7. ИК-спектр образца ханнебахитовой коры (а) и ханнебахита из публикации [6] (б). 
ному интервалу и количеству воды с эталонным образцом [8] и опубликованными данными [5], независимо от режима продувки печи. На ТГ-кривой, снятой в атмосфере аргона до $1250^{\circ} \mathrm{C}$, наблюдается ступенчатое уменьшение массы, связанное с десульфатизацией как гипса, так и безводного сульфита кальция. Природа экзопика при $939{ }^{\circ} \mathrm{C}$ на ДСКкривой (см. рис. 6), снятой на воздухе пока не выяснена.

ИК-спектроскопия (рис. 7) также подтвердила ханнебахитовый состав пробы: широкая полоса поглощения $3403 \mathrm{~cm}^{-1}$, а также $1628 \mathrm{~cm}^{-1}$ отвечает валентным колебаниям воды; полосы поглощения 984, 951 и $652 \mathrm{~cm}^{-1}$ характерны для валентных колебании $\mathrm{SO}^{3-}$. Кроме того, есть две сильные полосы в 1497 и 1427 см$^{-1}$, которые отмечены, как характерные для синтетического эталонного «ханнебахита» [6]. В дальнейшем планируется провести ИК-спектроскопию на всех этапах нагревания образцов с ханнебахитом, чтобы понять химизм протекающих при этом процессов преобразования веществ, фиксирующихся на термограммах.

\section{Выводы}

Таким образом, результаты исследований показали, что минеральные корообразные новообразования из скруббера Читинской ТЭЦ1 состоят из полуводного сульфита кальция - ханннебахита. Это первая находка его в таких условиях образования. Ранее ханнебахит в условиях техногенеза фиксировался исследователями в скважинах нефтяных месторождений [1-3]. Помимо ханнебахита в состав зольных кор входит гипс (до 5 \%) и незначительная примесь барита. Дальнейшие исследования условий образования ханнебахита и других минеральных новообразований в технических системах ТЭЦ требуют применения методов физико-химического моделирования.

Авторы выражают благодарность к.г.-м.н. С. С. Потапову за консультации по теме исследования и помощь в поиске литературы, а также к.г.-м.н. О. К. Смирновой за помощь в проведении микрозондовых исследований.

\section{Литература}

1. Ершов В. В., Чесноков Б. В. Ханнебахит $\mathrm{CaSO}_{3} \times 1 / 2 \mathrm{H}_{2} \mathrm{O}-$ первая находка в СССР // Минералы месторождений и зон техногенеза рудных районов Урала. Свердловск: УрО АН СССР, 1990. С. 117-122.

2. Ершов В. В., Чесноков Б. В. Ханнебахит из нефтяных скважин Прикамья - вторая находка в мире // Тез. докл. школы-семинара молодых 
геологов «Геология, минералогия и полезные ископаемые Южного Урала». Миасс, 1987. С. 41-43.

3. Потапов С. С. Изучение минералообразования при добыче нефти и газа // Минералогия техногенеза-2000. Миасс: ИМин УрО РАН, 2000. С. 86-105.

4. Филенко Р. А. Техногенное минералообразование на золошлакоотвалах Читинской ТЭЦ-1 и ТЭЦ-2 // Минералогия техногенеза-2016. Миасс: ИМин УрО РAH, 2016. С. 137-148.

5. Jambor J. L., Bladh K. W., Ercit T. S., Grice J. D., Grew E. S. New mineral names // American Mineralogist. 1988. V. 73. P. 927-935 (928).

6. Postl W., Bernhard F. \& Bojar H.-P. Hannebachit aus dem Steinbruch am Stradner Kogel bei Wilhelmsdorf, Steiermark - erster Nachweis eines Sulfits in Österreich // Joannea - Mineralogie. 2008. V. 4. P. 115-125. (http://www.zobodat.at/ pdf/JoanneaMineralogie_4_0115-0125.pdf).

7. https://ruff.info/hannebachite/names/asc/

8. https://rruff.info/doclib/hom/hannebachite.pdf (Anthony J. W, Bideaux R. A, Bladh K. W, and Nichols M. C. Handbook of Mineralogy, Mineral Data Publishing, Tucson Arizona, USA, by permission of the Mineralogical Society of America, 1990). 